\title{
FLORA DA BAHIA: VIOLACEAE
}

\author{
$\underline{\text { José Florêncio Cerquiera Oliveira }^{1} \text {; Luciano Paganucci de Queiroz }}{ }^{2}$ \\ 1. Bolsista PIBIC/CNPq, Graduando em Ciências Biologicas, Universidade Estadual de Feira de Santana, e-mail: \\ jose.florencioco@gmail.com \\ 2. Professor Dr. Do Departamento de Ciências Biologicas, Universidade Estadual de Feira de Santana, \\ e-mail: luciano.paganucci@gmail.com
}

PALAVRAS-CHAVE: Taxonomia; Florística; Malpighiales.

\section{INTRODUÇÃO}

Violaceae possui distribuição cosmopolita e inclui 23 gêneros e cerca de 800 espécies. No Brasil ocorrem 14 gêneros e cerca de 80 espécies, a maioria em Pombalia Vand. e Rinorea Aubl. (Souza e Lorenzi 2012; Paula-Souza, 2009).

As Violaceae são ervas, árvores ou, menos frequentemente, lianas com folhas alternas espiraladas ou dísticas ou, menos frequentemente, opostas, simples, com estípulas conspícuas, persistentes ou caducas, raramente com pontuações translúcidas (Leonia Ruiz \& Pav.), inflorescência em pseudoracemo, racemo, cimeira simples ou composta, fascículo ou flores solitárias, flores geralmente bissexuadas, actinomorfas a fortemente zigomorfas, diclamídeas, cálice pentâmero, dialissépalo, persistente na frutificação, imbricado, labelo (pétala abaxial) giboso a longamente calcarado nas flores zigomorfas, estames (3-)5, filetes livres ou unidos entre si, anteras rimosas, geralmente com conectivo provido de um apêndice membranáceo e apical (em algumas espécies os dois estames anteriores, são provido de apêndices nectaríferos sobre os filetes), ovário súpero, (2-)3(-5)-carpelar, unilocular, placentação parietal, uni a pluriovulado, fruto cápsula, ás vezes membranácea e inflada (Anchietea e Hybanthopsis), raramente baga (Gloeospermum Triana \& Planch. e Leonia) ou noz (Leonia) (Souza \& Lorenzi 2012).

A família tradicionalmente é dividida em três subfamílias (Hekking 1988): Leonioideae, com flores actinomorfas, prefloração irregularmente imbricada, representada apenas pelo gênero sul-americano Leonia; Violoideae, com flores actinomorfas ou zigomorfas, prefloração coclear distal ou quincucial; Fusispermoideae, com flores actinomorfas, prefloração convoluta, representada pelo gênero Fusispermum Cuatrec. Paula-Souza (2009) realizou estudos filogenéticos na tribo Violeae e observou que Violoideae não é monofilética. Nesse mesmo trabalho também foi constatado o não monofiletismo de Hybanthus o que levou ao restabelecimento de Pombalia (PaulaSouza 2014), transferindo assim para este último gênero várias espécies listadas para a Bahia. No entanto, algumas espécies foram mantidas em Hybanthus mesmo apresentando características que sustentariam sua transferência para Pombalia. Essa mesma autora aponta a necessidade de uma melhor diferenciação entre Pombalia e Hybanthus (Paula-Souza 2009).

Apesar dos avanços no conhecimento da taxonomia da família, não existe um levantamento de Violaceae para o estado da Bahia, que é o objetivo do presente trabalho.

\section{MATERIAL E MÉTODOS}

Foram realizadas expedições para amostragem das espécies nativas da Bahia, especialmente os gêneros mal representados nos herbários. Foram priorizadas viagens para municípios onde havia informação de presença de espécies pouco coletadas. 
Selecionado cidades da Chapada Diamantina para coleta de material botânico (Abaíra, Catolés, Ituaçu e Tanhaçu).

Foram analisadas as coleções dos principais herbários da Bahia (ALCB, CEPEC, HUEFS). Tipos nomenclaturais de táxons da Bahia foram analisados através de imagens disponibilizadas na internet, especialmente no site do JStor Plant Science (http://plants.jstor.org), do Species Link (http://splink.cria.org.br/) e do Reflora (http://floradobrasil.jbrj.gov.br/).

As espécies foram identificadas através da análise das obras príncipes e comparação com imagens dos tipos nomenclaturais disponíveis. As descrições morfológicas foram feitas com base em espécimes coletados na Bahia. Eventualmente, espécimes coletados fora do estado poderão ser usados para complementar à descrição de partes ausentes.

\section{RESULTADOS E DISCUSSÃO}

Na Bahia foi catalogado para Violaceae nove gêneros e 25 espécies, sendo o maior gênero Pombalia com doze espécies: $P$. arenaria (Ule) Paula-Souza, $P$. atropurpurea (A.St.-Hil.) Paula-Souza, P. barbata Paula-Souza, P. brevicaulis (Mart.) Paula-Souza, $P$. calceolaria (L.) Paula-Souza, $P$. communis (A.St.-Hil.) Paula-Souza, $P$. glauca (Chodat) Paula-Souza, P. heterosepala (Eichler) Paula-Souza, P. lanata (A.St.Hil.) Paula-Souza, P. oppositifolia (L.) Paula-Souza, P. setigera (A.St.-Hil.) PaulaSouza, P. verrucosa (Paula-Souza) Paula-Souza. Os demais gêneros encontrados na Bahia são: Amphirrhox Spreng. (1 espécie), Anchietea A.St.-Hil. (3), Hybanthopsis Paula-Souza (1), Hybanthus Jacq. (1), Noisettia Kunth (1), Paypayrola Aubl. (2), Rinorea Aubl. (3), Schweiggeria Spreng. (1), sendo Anchietea ferrucie Paula-Souza \& Zmarzty, e Pombalia heterosepala endêmicos da Bahia. Hybanthopsis bahiensis PaulaSouza, anteriormente considerada endêmica da Bahia, foi recentemente registrada para a Serra da Guia no estado de Sergipe.

\section{Chave para os Gêneros de Violaceae da Bahia}

1. Habito não arbóreo; flores claramente zigomorfas

2. Arbusto escandescente.

3. Trepadeiras; folhas com base cordada; sementes pilosa com duas projeções na base.

Hybanthopsis

3. Lianas; folhas com base aguda a cuneada; sementes glabras sem projeções na base.

Anchietea

2'. Erva; arbusto ou subarbusto.

4. Três sépalas externas e duais internas; estigma trilobado (sendo um dos lobos pouco visível)

Schweiggeria

4'. Todas as sépalas externas; estigma simples ........................................................5

5. Inflorescência em fascículos axilares .Noisetia

5'. Inflorescência dispostas de outra forma .6

6. Papilas presentes na face abaxial das folhas, gineceu e androceu Hybanthus

6 '. Papilas ausentes em toda a planta Pombalia 
1'. Hábito arbóreo; flores actinomorfa ou levemente zigomorfas

7. Flores não tubulares; estames livres entre si, raramente fundidos na base ....Rinorea

7'. Flores tubulares; estames fundidos na base

8. Inflorescência em dicásio; estilete maior que $5 \mathrm{~mm}$ compr.; apêndice do conectivo afilado no ápice da antera (cerca de $2 \mathrm{~mm}$ compr.)

Amphirrhox

8'. Inflorescência racemosa; estilete menor que $4 \mathrm{~mm}$ compr.; apêndice do conectivo retangular no ápice da antera (ca. $1 \mathrm{~mm}$ compr.)

Paypayrola
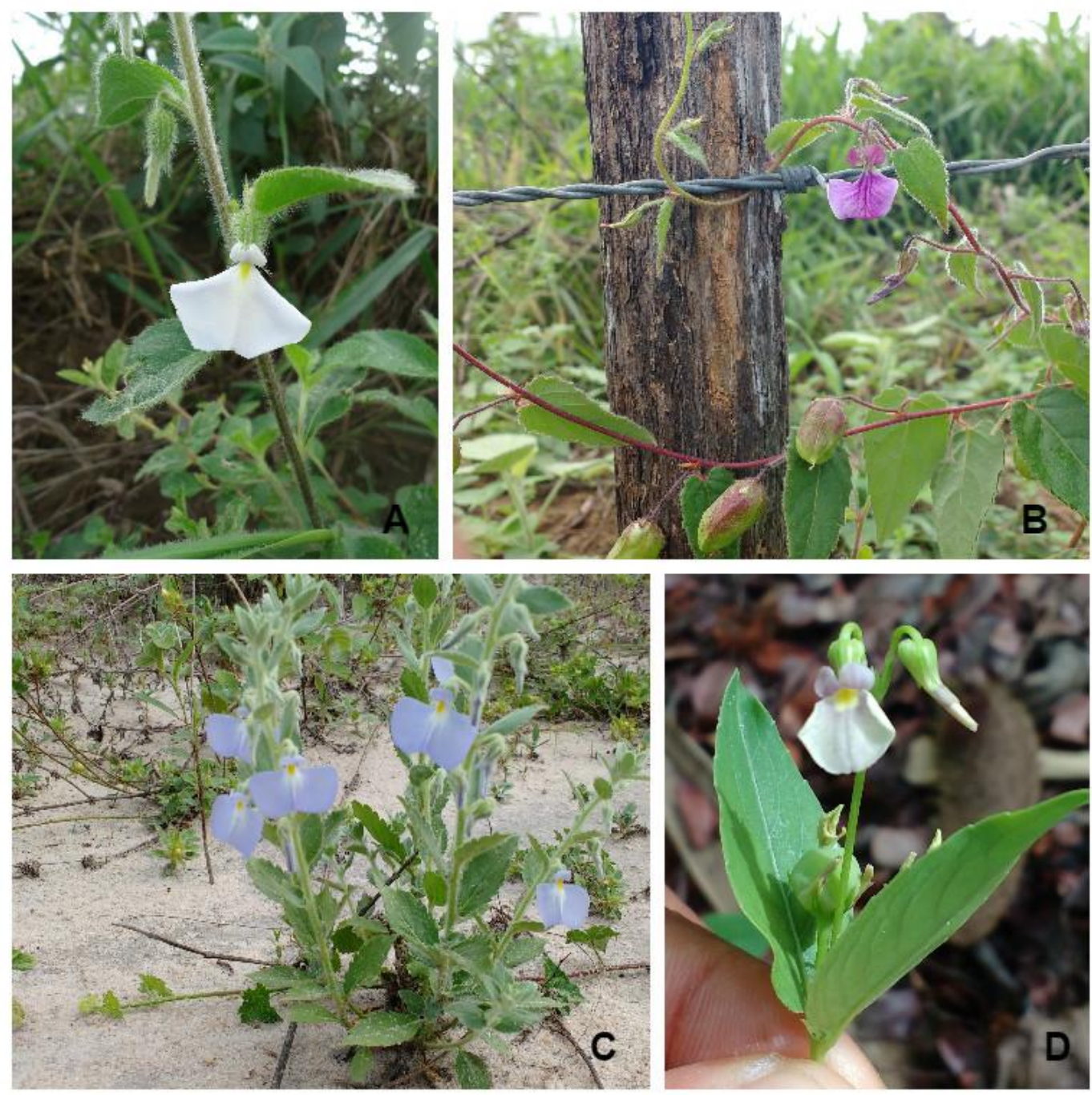

Figura 1: Espécies de Violaceae coletadas na Bahia. A - Pombalia calceolaria; B - Hybanthopsis bahiensis; C- Pombalia arenaria;. D - Pombalia glauca.

\section{CONSIDERAÇÕES FINAIS}

A família Violaceae apresenta ampla distribuição no estado da Bahia. Tendo o gênero Pombalia o maior numero de representantes no estado. Ainda fazem-se necessárias excussões botânicas para amostragem das espécies pouco representadas em herbários. Problemas taxonômicos ainda dentro da família apontam para a necessidade de maiores estudos em Violaceae. 


\section{REFERÊNCIAS}

Hekking, W. H. A. 1988. Monograph 46. Violaceae Part I-Rinorea and Rinoreocarpus. Flora Neotropica Monograph 26: 1-207.

PAULA-SOUZA1, J. 2003. Levantamento das espécies de Hybantus Jacq. (Violaceae) do Brasil. (Mestrado). Univ. São Paulo.

PAULA-SOUZA1, J. 2009. Estudos Filogenéticos em Violaceae com ênfase na Tribo Violeae e Revisão Taxonômica dos Gêneros Lianescentes de Violaceae na região Neotropical. (Doutorado). Univ. São Paulo. 259p.

Souza, V.C. \& Lorenzi, H. 2012. Botânica Sistemática: guia ilustrativo para identificação das famílias de fanerógamas nativas e exóticas no Brasil, baseado em APG II. $3^{\mathrm{a}}$ ed. $768 \mathrm{p}$. 